\title{
Blood flow distribution in a large series of patients having the Fontan operation: A cardiac magnetic resonance velocity mapping study
}

\author{
Kevin K. Whitehead, MD, PhD, ${ }^{a}$ Kartik S. Sundareswaran, MS, ${ }^{b}$ W. James Parks, MD, ${ }^{c}$ \\ Matthew A. Harris, MD, ${ }^{\text {a }}$ Ajit P. Yoganathan, PhD, ${ }^{\mathrm{b}}$ and Mark A. Fogel, MD, FACC ${ }^{\mathrm{a}}$
}

\begin{abstract}
Objectives: Our goal was to determine flow distribution in the cavopulmonary connections of patients with and without bilateral superior venae cavae who had the Fontan procedure. No large series exists that establishes the flow distributions in Fontan patients, which would be an important resource for everyday clinical use and may affect future surgical reconstruction.
\end{abstract}

\begin{abstract}
Methods: We studied 105 Fontan patients (aged 2-24 years) with through-plane phase contrast velocity mapping to determine flow rates in the inferior and superior venae cavae and left and right pulmonary arteries. Superior caval anastomosis type included 40 bidirectional Glenn shunts (of which 15 were bilateral) and 53 hemi-Fontan anastomoses; Fontan type included 69 intra-atrial baffles, 28 extracardiac conduits, and 4 atriopulmonary connections.
\end{abstract}

Results: Total caval flow was $2.9 \pm 1.0 \mathrm{~L} \cdot \mathrm{min}^{-1} \cdot \mathrm{m}^{-2}$, with an inferior vena cava contribution of $59 \% \pm 15 \%$. Total pulmonary flow was $2.5 \pm 0.8 \mathrm{~L} \cdot \mathrm{min}^{-1} \cdot \mathrm{m}^{-2}$, statistically less than caval flow and not explained by fenestration presence. The right pulmonary artery contribution $(55 \% \pm 13 \%)$ was statistically greater than the left. In patients with bilateral superior cavae, the right cava accounted for $52 \% \pm 14 \%$ of the flow, with no difference in pulmonary flow splits $(50 \% \pm 16 \%$ to the right). Age and body surface area correlated with percent inferior caval contribution ( $r=0.60$ and 0.74 , respectively). Superior vena cava anastomosis and Fontan type did not significantly affect pulmonary flow splits.

Conclusions: Total Fontan cardiac index was $2.9 \mathrm{~L} \cdot \mathrm{min}^{-1} \cdot \mathrm{m}^{-2}$, with normal pulmonary flow splits $(55 \%$ to the right lung). Inferior vena caval contribution to total flow increases with body surface area and age, consistent with data from healthy children.

In the early 1970s, Fontan, ${ }^{1}$ Kreutzer, ${ }^{2}$ and their associates independently developed strategies for palliation in patients with tricuspid atresia that involved baffling the caval veins directly to the pulmonary arteries. This strategy has since been modified and adopted for the treatment of all patients with a single usable ventricle. ${ }^{3-7}$ Staged reconstruction of the modified Fontan operation has become the standard by which single ventricle is palliated. Despite success at many institutions, managing these patients remains one of the most controversial and challenging aspects of pediatric cardiology.

During routine management, it may be useful to measure flow rates in various parts of the systemic venous pathway to

From the Division of Cardiology, ${ }^{\text {a }}$ Children's Hospital of Philadelphia, Philadelphia, $\mathrm{Pa}$; the Department of Biomedical Engineering, ${ }^{\mathrm{b}}$ Georgia Institute of Technology and Emory University; and the Sibley Heart Center, ${ }^{\mathrm{c}}$ Children's Health Care of Atlanta, Emory University School of Medicine, Atlanta, Ga.

This work was supported in part by the National Institutes of Health BRP Grant R01 HL 67622 and by the Pediatric Heart Network Fontan cross-sectional study 5U01HL68279-03.

Received for publication Jan 28, 2008; revisions received Oct 20, 2008; accepted for publication Nov 23, 2008.

Address for reprints: Kevin K. Whitehead, MD, PhD, Cardiology, 2nd Floor Main Bldg, Children's Hospital of Philadelphia, Philadelphia, PA 19104 (E-mail: whiteheadk@email.chop.edu).

J Thorac Cardiovasc Surg 2009;138:96-102

$0022-5223 / \$ 36.00$

Copyright (c) 2009 by The American Association for Thoracic Surgery doi:10.1016/j.jtcvs.2008.11.062 make management decisions. This allows measurement of cardiac output and the determination of flow splits to the pulmonary arteries. Measurement of these flows may also prove to be beneficial in planning future surgical reconstructions. Cardiac magnetic resonance imaging (CMR) provides an accurate, noninvasive means of measuring flow rate in each limb of the cavopulmonary connection. ${ }^{8,9}$ However, no large series exists that has used CMR to investigates the flow rates and distributions in patients having the Fontan operation. The goal of the study was to determine blood flow distribution and flow rates in these patients using CMR in the inferior and superior venae cavae (IVC and SVC) and the left and right pulmonary arteries (LPA and RPA). These data will serve as a guide for the clinical management of these patients. In addition, the effect of patient age and size, presence or absence of left SVC, and Fontan type on both the IVC contribution to total Fontan flow and LPA/ RPA flow splits are determined.

\section{METHODS}

Patients

We studied 105 subjects with CMR phase-contrast velocity mapping. They were enrolled at either Children's Hospital of Philadelphia (CHOP) or Children's Healthcare of Atlanta (CHOA) over a 6-year period from March 2001 through June 2007. All protocols were approved by the 

Abbreviations and Acronyms
$\mathrm{BSA}=$ body surface area
CHOA $=$ Children's Healthcare of Atlanta
$\mathrm{CHOP}=$ Children's Hospital of Philadelphia
$\mathrm{CMR}=$ cardiac magnetic resonance imaging
IVC = inferior vena cava
LPA = left pulmonary artery
MRI = magnetic resonance imaging
RPA = right pulmonary artery
$\mathrm{SVC}=$ superior vena cava

institutional review boards of both institutions and informed consent was obtained from all participants or their legal guardians.

The mean subject age was 11.5 years, ranging from 2 to 28 years. The mean time from the Fontan operation for the 82 patients for whom the data were available was 8.2 years. The SVC anastomosis and Fontan type were recorded from the medical record for each patient, when available. There were 40 patients with bidirectional Glenn shunts, 53 with hemi-Fontans, and 12 who either had older atriopulmonary-type connections or else had insufficient information to determine the type of SVC connection. The Fontan type included 69 intra-atrial baffles, 28 extracardiac conduits, and 4 classic atriopulmonary connections. Four patients had their operations at outside institutions and their Fontan types were not completely defined. There were 15 patients with bilateral SVCs. The presence of an open fenestration was recorded by the surgical note determining whether there was a surgical fenestration and by the most recent echocardiogram documenting whether the fenestration was still patent.

All patients were required to undergo a 1-hour magnetic resonance imaging (MRI) scan. Older patients performed breath-holds for image acquisition, whereas younger patients or patients unable to cooperate were sedated per institution protocol and averaging was used. No patient had arrhythmias that precluded imaging in the scanner. Patients were excluded if artifact precluded obtaining velocity maps in all 4 or 5 (for bilateral SVCs) limbs of the Fontan pathway.

\section{CMR}

All CMR scans were performed at either CHOP or CHOA using either a 1.5-T Siemens Magnetom Avanto (Siemens Medical Systems, Iselin, NJ) or a 1.5-T GE Signa (GE Medical Systems, Milwaukee, Wis). Velocity maps of each venous vessel (SVC, IVC, left SVC) and pulmonary artery (LPA, RPA) were obtained. In addition, aortic outflow was available in 78 patients. Five patients were excluded from the study for artifact in one or both pulmonary arteries.

\section{Phase-Encoded Velocity Mapping}

Retrospectively gated, through-plane phase-encoded velocity maps were obtained in the SVC, IVC, RPA, and LPA and in most cases of the proximal ascending aorta. Care was taken to be perpendicular to flow and to obtain slice positions and orientations that were (1) distal to the azygos insertion (when still present) into the SVC, (2) proximal to the RPA upper lobe branching, and (3) distal to the aorta-pulmonary anastomosis (if present). Multiplanar reconstruction was used to set the position and angle of the imaging plane for phase-encoded velocity mapping. A set of sample parameters is given in Table 1 .

\section{Data Analysis}

An in-house program in Matlab (The Mathworks, Natick, Mass) was used to read and process acquired images. A gradient-based active contour algorithm was implemented for the semiautomatic segmentation of the ves- sel of interest in all the cardiac phases. ${ }^{10}$ A contour was manually outlined around the vessel of interest. This contour would automatically evolve on the basis of gradient-based forces until it identified the vessel boundary for all the cardiac phases. The segmentation was visually inspected for accuracy, and incorrect contours were adjusted manually. The segmented pixel values were converted into velocity values, which were integrated over the entire vessel area for each cardiac phase to extract flow for that phase. Mean flow rates were computed by averaging the flows through all the cardiac phases.

These flows were indexed to body surface area (BSA) for comparison. Fractional contributions of IVC and RPA to total blood flow were calculated and correlated with BSA and age. All population statistics are reported as a mean \pm the standard deviation. Differences between statistics are reported as mean difference \pm the standard error. Total pulmonary blood flow, total caval blood flow, and aortic flow were compared using a paired Student $t$ test. The data were disaggregated by Fontan type, SVC anastomosis type, and the presence or absence of a left SVC. These groups were compared by Student $t$ test for independent samples to determine whether flow splits vary by group.

\section{RESULTS}

The results of the Fontan flow analysis are summarized in Table 2. The contribution of IVC flow to total systemic venous return was $59 \% \pm 15 \%$. The contribution of RPA flow to total pulmonary blood flow was $55 \% \pm 13 \%$, which was significantly greater than half $(P=.003)$. Total pulmonary flow was measured at $2.4 \pm 0.7 \mathrm{~L} \cdot \mathrm{min}^{-1} \cdot \mathrm{m}^{-2}$, compared with $2.8 \mathrm{~L} \cdot \mathrm{min}^{-1} \cdot \mathrm{m}^{-2}$ for the measured total caval flow, a difference of $14 \%(P<.001)$.

In patients with bilateral SVCs, the right SVC accounted for $52 \% \pm 14 \%$ of the flow. No difference was noted in the pulmonary flow splits for patients with bilateral SVCs, with $48 \% \pm 19 \%$ to the right lung.

A potential source of difference between the systemic venous and pulmonary flows is the presence of a fenestration in the Fontan repair, which would allow a right-to-left shunt before blood reaches the branch pulmonary arteries. To investigate this, the data were disaggregated by the presence or absence of a fenestration at the time of the MRI. Although the ratio of pulmonary to caval blood flow was slightly higher in patients without an open fenestration $(0.86 \pm$ 0.24 vs $0.84 \pm 0.20$ ), the difference was small and not statistically significant.

Age and BSA were correlated with the IVC fraction of total systemic venous return ( $r=0.60$ and 0.74 , respectively; $P<.05)$. The IVC fraction appeared to increase in a logarithmic pattern with BSA (Figure 1). Conversely, there was no correlation between RPA fraction of pulmonary blood flow and age or BSA.

\section{Effect of Left SVC and Fontan Type}

Table 2 summarizes the comparison of patients with bilateral SVCs with those without, and it compares those with intracardiac versus extracardiac Fontans. There was no significant effect of SVC anastomosis type, Fontan type, or presence of a left SVC on the pulmonary flow splits or the fractional contribution of the IVC to caval flow. 
TABLE 1. Example of velcotiy mapping parameters

\begin{tabular}{lcllc}
\hline \multicolumn{1}{c}{ Parameter } & Setting & & Parameter \\
\hline TR $(\mathrm{ms})$ & 50 & Asymmetric echo allowed R-R $=750 \mathrm{~ms}$ & \multicolumn{1}{c}{ VENC $(\mathrm{cm} / \mathrm{s})$} & \multicolumn{1}{c}{$50-150^{*}$} \\
TE $(\mathrm{ms})$ & 3.8 & & Rectangular FOV \\
FOV $(\mathrm{mm})$ & 250 & & Acquisition window \\
Thickness $(\mathrm{mm})$ & 5 & Flip angle (deg) & $750 \mathrm{~ms}$ \\
Phases (calculate) & 25 & Measured phases: 14 & Segments & 25 \\
Matrix & $127 \times 256$ & & Partial phase Fourier & 3 \\
NEX & 3 & & Bandwidth (Hz/px) & 0 \\
\hline
\end{tabular}

$T R$, Repetition time; $T E$, echo time; $F O V$, field of view; $N E X$, number of excitations; $V E N C$, velocity encoding. *The setting of 50 to 80 used for the superior and inferior venae cavae and the right and left pulmonary arteries; 150 was used for the aorta.

The ratio of pulmonary to caval flow is not statistically different from unity for the extracardiac Fontans. However, the mean ratio of pulmonary to caval flow for the intracardiac Fontans is statistically different from unity. The BSA and age in the extracardiac Fontans were significantly lower than those of the lateral tunnel Fontans. This reflects recent surgical trends and thus makes direct comparison of caval contributions as a function of Fontan type with regard to age and BSA difficult in this study.

\section{Effect of Ventricular Morphology and Type of Congenital Heart Disease}

The first part of Table 3 summarizes the flow results for patients with dominant right (62 patients) or left ventricles (37 patients). The remaining 6 patients either had a morphologically ambiguous systemic ventricle or had two good sized ventricles. There were no significant differences between the two groups. The most common types of congenital heart disease included hypoplastic left heart syndrome (42 patients), tricuspid atresia (18 patients), various forms of double-outlet right ventricle (15 patients), D-transposition of the great arteries (8 patients), and pulmonary atresia with intact ventricular septum (7 patients). The remaining patients were a mix of more unusual substrates. The only significant finding was that the indexed caval flow for the group with pulmonary atresia and intact ventricular septum $(2.2 \mathrm{~L}$. $\min ^{-1} \cdot \mathrm{m}^{-2}$ ) was significantly less than that for the group with hypoplastic left heart syndrome $\left(2.8 \mathrm{~L} \cdot \mathrm{min}^{-1}\right.$. $\mathrm{m}^{-2}$ ). Note that the aortic flow did not follow this trend, suggesting that this group may tend to have greater aortopulmonary collateral flow.

\section{Effect of Breath-Holding on Measured Flows}

There were 71 patients who performed breath-holding during the phase contrast magnetic resonance velocity mapping acquisitions, whereas 34 patients were sedated and free breathing. There were no significant differences between the two groups.

\section{Comparing Fontan Flows With Aortic Flow}

When compared with aortic flow data, the measured caval flow was generally about $12 \%$ lower across the range of measured flows (Table 4). The measured pulmonary blood flow was about $22 \%$ lower on average. This appears to be

TABLE 2. Summary of velocimetry data for caval and pulmonary artery flows and comparisons between the presence and absence of an LSVC and Fontan type

\begin{tabular}{|c|c|c|c|c|c|c|}
\hline $\begin{array}{c}\text { Flows }\left(\mathbf{L} \cdot \min ^{-1} \cdot \mathbf{m}^{-2}\right) \\
\text { Ratios as fraction }\end{array}$ & $\begin{array}{c}\text { No LSVC } \\
90 \\
\text { Mean } \pm \text { SD } \\
\end{array}$ & $\begin{array}{c}\text { With LSVC } \\
15 \\
\text { Mean } \pm \text { SD } \\
\end{array}$ & $\begin{array}{c}\text { LSVC } \\
\text { vs no } \\
\text { LSVC } \\
P \text { value } \\
\end{array}$ & $\begin{array}{c}\text { Intracardiac } \\
\text { Fontan } \\
69 \\
\text { Mean } \pm \text { SD } \\
\end{array}$ & $\begin{array}{c}\text { Extracardiac } \\
\text { Fontan } \\
28 \\
\text { Mean } \pm \text { SD } \\
\end{array}$ & $\begin{array}{c}\text { Intracardiac vs } \\
\text { extracardiac } \\
P \text { value } \\
\end{array}$ \\
\hline Age & $11.0 \pm 5.8$ & $14.8 \pm 6.9$ & .03 & $11.9 \pm 5.5$ & $8.5 \pm 4.9$ & .005 \\
\hline BSA & $1.13 \pm 0.44$ & $1.41 \pm 0.55$ & .03 & $1.2 \pm 0.5$ & $0.9 \pm 0.3$ & .003 \\
\hline$(\mathrm{IVC}+\mathrm{SVC}) / \mathrm{BSA}$ & $2.9 \pm 1.0$ & $2.7 \pm 0.8$ & .61 & $2.8 \pm 1.0$ & $3.0 \pm 1.0$ & .43 \\
\hline$(\mathrm{RPA}+\mathrm{LPA}) / \mathrm{BSA}$ & $2.5 \pm 0.8$ & $2.2 \pm 0.6$ & .17 & $2.3 \pm 0.8$ & $2.7 \pm 0.8$ & .03 \\
\hline IVC/(IVC+SVC) & $0.59 \pm 0.15$ & $0.61 \pm 0.11$ & .59 & $0.60 \pm 0.15$ & $0.55 \pm 0.11$ & .17 \\
\hline RPA/(LPA + RPA) & $0.55 \pm 0.13$ & $0.50 \pm 0.16$ & .22 & $0.55 \pm 0.13$ & $0.51 \pm 0.13$ & .14 \\
\hline$(\mathrm{RPA}+\mathrm{LPA}) /(\mathrm{IVC}+\mathrm{SVC})$ & $0.92 \pm 0.2$ & $1.1 \pm 1.7$ & .38 & $0.88 \pm 0.3$ & $1.26 \pm 1.9$ & .1 \\
\hline $\mathbf{n}$ & 67 & 11 & & 52 & 22 & \\
\hline Aortic flow/BSA & $3.7 \pm 1.6$ & $3.2 \pm 0.7$ & .40 & $3.4 \pm 1.5$ & $4.1 \pm 1.5$ & .11 \\
\hline$(\mathrm{IVC}+\mathrm{SVC}) / \mathrm{Ao}$ & $0.88 \pm 0.5$ & $0.88 \pm 0.2$ & .99 & $0.92 \pm 0.5$ & $0.82 \pm 0.3$ & .41 \\
\hline$(\mathrm{RPA}+\mathrm{LPA}) / \mathrm{Ao}$ & $0.78 \pm 0.6$ & $0.73 \pm 0.3$ & .79 & $0.80 \pm 0.6$ & $0.70 \pm 0.2$ & .48 \\
\hline
\end{tabular}

$L S V C$, Left superior vena cava; $S D$, standard deviation; $B S A$, body surface area; $I V C$, inferior vena cava; $S V C$, superior vena cava; $R P A$, right pulmonary artery; $L P A$, left pulmonary artery; $A o$, aorta. All values reported as mean \pm standard deviation. 


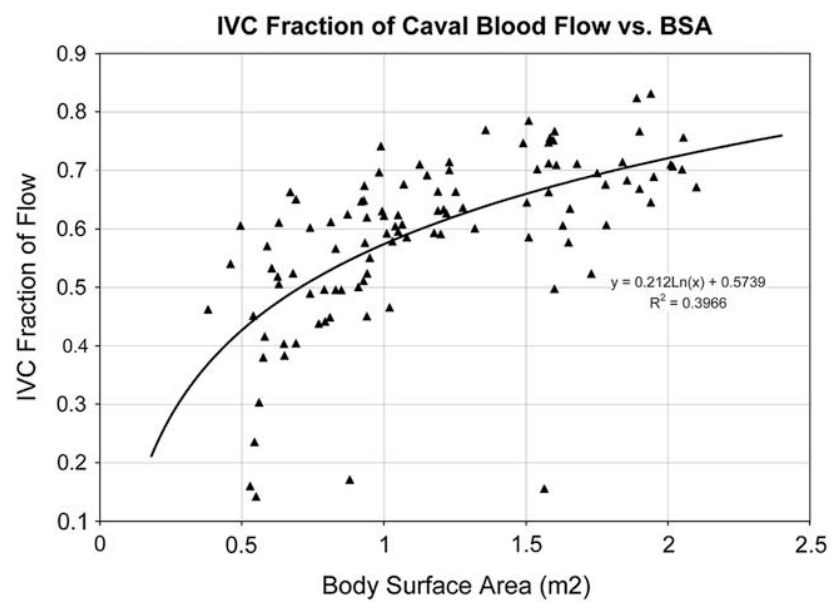

FIGURE 1. Relationship between the inferior vena caval (IVC) fraction of caval flow and body surface area $(B S A)$. There was a strong correlation between IVC fraction and BSA; $\mathrm{y}=0.2 \ln (\mathrm{x})+0.57, r=0.72, P<.05$.

primarily a systematic rather than random difference, inasmuch as Figure 2 demonstrates that there was excellent correlation between the total pulmonary blood flow, total caval blood flow, and aortic flow. Note in the Bland-Altman plot for the caval data that there are almost no data points in which the caval flow exceeds aortic flow, with most patients having measured caval flow significantly less than the aortic flow. Five significant outliers in these data were excluded from the correlation. The linear regression of caval and pulmonary flows with aortic flow demonstrates excellent correlation, but with slopes significantly less than unity.

\section{DISCUSSION}

The current study is the largest to date in measuring Fontan flow distribution in the systemic venous pathway. Its agreement with prior data using both mass spectrometry ${ }^{11}$ and the Fick method ${ }^{12,13}$ suggests that CMR can accurately measure blood flow in the Fontan baffle. The importance of a large series of patients in establishing normative data for this unique population should not be understated. Prior series are at best anecdotal and certainly cannot be viewed as establishing normal values.

Many investigators, including us, are performing computer and in vitro modeling of the Fontan pathway to better understand the hemodynamics of the connection. Many investigators rely on normal values reported in the literature on which to base their models. Inasmuch as the previously reported series have been quite limited, we believe the current data will provide a more comprehensive range of normal flows and flow splits on which investigators can base their models.

This study demonstrated that total caval flow was $2.9 \mathrm{~L}$. $\min ^{-1} \cdot \mathrm{m}^{-2}$, with measured total pulmonary flow slightly less, and an IVC contribution of nearly $60 \%$. Flows to both lungs and from both SVCs, when present, were nearly equal. Type of SVC anastomosis or Fontan did not significantly affect pulmonary flow splits. Age and BSA were correlated with IVC contribution.

There was a relatively small but significant difference between measured pulmonary and systemic venous flow. Part of this may be explained by Fontan fenestration, although attempts to control for this did not account for the differences. One potential source may be in the measurement of the RPA flow, as the origin of the right upper lobe branch of the pulmonary artery is often extremely close to the SVC-RPA junction. It is therefore often very challenging to choose an imaging plane that will exclude the SVC but include the right upper lobe branch.

There was excellent correlation between aortic and both pulmonary and venous flow measurements. However, the measured systemic venous and pulmonary artery flows

TABLE 3. Summary of velocimetry data and comparisons between the systemic LV and RV, as well as summaries of flows for breath-held versus free breathing

\begin{tabular}{|c|c|c|c|c|c|c|}
\hline $\begin{array}{c}\text { Flows }\left(\mathrm{L} \cdot \min ^{-1} \cdot \mathbf{m}^{-2}\right) \\
\text { Ratios as fraction } \\
n\end{array}$ & $\begin{array}{c}\text { RV } \\
62 \\
\text { Mean } \pm \text { SD } \\
\end{array}$ & $\begin{array}{c}\text { LV } \\
37 \\
\text { Mean } \pm \text { SD } \\
\end{array}$ & $\begin{array}{c}\text { RV vs } L V \\
P \text { value }\end{array}$ & $\begin{array}{l}\text { Breath-held } \\
\quad 71 \\
\text { Mean } \pm \text { SD } \\
\end{array}$ & $\begin{array}{c}\text { Free breathing } \\
34 \\
\text { Mean } \pm \text { SD } \\
\end{array}$ & $\begin{array}{l}\text { Breath-held vs free breathing } \\
\qquad P \text { value } \\
\end{array}$ \\
\hline Age & $11.6 \pm 5.8$ & $12.5 \pm 6.1$ & .4 & $12.7 \pm 5.9$ & $9.4 \pm 5.8$ & .01 \\
\hline BSA & $1.15 \pm 0.47$ & $1.26 \pm 0.44$ & .27 & $1.2 \pm 0.5$ & $1.0 \pm 0.5$ & .02 \\
\hline$(\mathrm{IVC}+\mathrm{SVC}) / \mathrm{BSA}$ & $2.9 \pm 0.8$ & $2.8 \pm 1.2$ & .66 & $2.7 \pm 1.0$ & $3.0 \pm 0.9$ & .13 \\
\hline$(\mathrm{RPA}+\mathrm{LPA}) / \mathrm{BSA}$ & $2.4 \pm 0.8$ & $2.5 \pm 0.8$ & .74 & $2.5 \pm 0.8$ & $2.4 \pm 0.7$ & .92 \\
\hline IVC/(IVC + SVC) & $0.61 \pm 0.11$ & $0.58 \pm 0.16$ & .23 & $0.60 \pm 0.14$ & $0.57 \pm 0.15$ & .24 \\
\hline $\mathrm{RPA} /(\mathrm{LPA}+\mathrm{RPA})$ & $0.55 \pm 0.13$ & $0.52 \pm 0.14$ & .34 & $0.53 \pm 0.13$ & $0.57 \pm 0.14$ & .17 \\
\hline$(\mathrm{RPA}+\mathrm{LPA}) /(\mathrm{IVC}+\mathrm{SVC})$ & $0.87 \pm 0.24$ & $1.2 \pm 1.7$ & .13 & $1.05 \pm 1.2$ & $0.84 \pm 0.2$ & .31 \\
\hline $\mathbf{n}$ & $\mathbf{5 0}$ & 25 & & 46 & 32 & \\
\hline Aortic flow/BSA & $3.5 \pm 1.6$ & $3.7 \pm 1.3$ & .67 & $3.5 \pm 1.8$ & $3.7 \pm 0.95$ & .61 \\
\hline$(\mathrm{IVC}+\mathrm{SVC}) / \mathrm{Ao}$ & $0.93 \pm 0.5$ & $0.82 \pm 0.3$ & .32 & $0.90 \pm 0.6$ & $0.86 \pm 0.2$ & .69 \\
\hline$(\mathrm{RPA}+\mathrm{LPA}) / \mathrm{Ao}$ & $0.82 \pm 0.6$ & $0.72 \pm 0.2$ & .43 & $0.84 \pm 0.7$ & $0.68 \pm 0.2$ & .18 \\
\hline
\end{tabular}

$L V$, Left ventricle; $R V$, right ventricle; $S D$, standard deviation; $B S A$, body surface area; $I V C$, inferior vena cava; $S V C$, superior vena cava; $R P A$, right pulmonary artery; $L P A$, left pulmonary artery; Ao, aorta. All values reported as mean \pm standard deviation. 
TABLE 4. Summary of velocimetry data by heart disease

\begin{tabular}{|c|c|c|c|c|c|}
\hline $\begin{array}{c}\text { Flows }\left(\mathrm{L} \cdot \mathrm{min}^{-1} \cdot \mathbf{m}^{-2}\right) \\
\text { Ratios as fraction } \\
\mathbf{n}\end{array}$ & $\begin{array}{c}\text { HLHS } \\
42\end{array}$ & $\begin{array}{l}\text { Tricuspid atresia } \\
\qquad 18\end{array}$ & $\begin{array}{l}\text { DORV } \\
15\end{array}$ & $\begin{array}{c}\text { PA-IVS } \\
7\end{array}$ & $\begin{array}{c}\text { D-TGA } \\
8\end{array}$ \\
\hline Age & $10.0 \pm 5.0$ & $11.4 \pm 6.5$ & $13.6 \pm 7.1$ & $15.0 \pm 3.9$ & $14.9 \pm 7.4$ \\
\hline BSA & $1.09 \pm 0.42$ & $1.16 \pm 0.47$ & $1.24 \pm 0.49$ & $1.4 \pm 0.23$ & $1.3 \pm 0.6$ \\
\hline$(\mathrm{IVC}+\mathrm{SVC}) / \mathrm{BSA}$ & $2.8 \pm 0.7$ & $3.2 \pm 1.4$ & $3.1 \pm 1.0$ & $2.2 \pm 0.8$ & $3.0 \pm 1.1$ \\
\hline$(\mathrm{RPA}+\mathrm{LPA}) / \mathrm{BSA}$ & $2.3 \pm 0.7$ & $2.7 \pm 1.0$ & $2.9 \pm 0.9$ & $2.2 \pm 0.7$ & $2.4 \pm 1.1$ \\
\hline IVC/(IVC+SVC) & $0.60 \pm 0.12$ & $0.54 \pm 0.17$ & $0.60 \pm 0.10$ & $0.62 \pm 0.21$ & $0.65 \pm 0.11$ \\
\hline RPA/(LPA + RPA) & $0.56 \pm 0.12$ & $0.49 \pm 0.13$ & $0.51 \pm 0.08$ & $0.60 \pm 0.22$ & $0.50 \pm 0.11$ \\
\hline$(\mathrm{RPA}+\mathrm{LPA}) /(\mathrm{IVC}+\mathrm{SVC})$ & $0.85 \pm 0.26$ & $0.9 \pm 0.27$ & $0.95 \pm 0.21$ & $1.0 \pm 0.18$ & $0.82 \pm 0.21$ \\
\hline $\mathbf{n}$ & 32 & 10 & 12 & 4 & 4 \\
\hline Aortic flow/BSA & $3.3 \pm 0.8$ & $3.9 \pm 1.6$ & $3.7 \pm 1.5$ & $3.2 \pm 0.3$ & $2.8 \pm 0.6$ \\
\hline$(\mathrm{IVC}+\mathrm{SVC}) / \mathrm{Ao}$ & $0.88 \pm 0.22$ & $0.88 \pm 0.16$ & $0.90 \pm 0.17$ & $0.78 \pm 0.10$ & $1.0 \pm 0.3$ \\
\hline$(\mathrm{RPA}+\mathrm{LPA}) / \mathrm{Ao}$ & $0.74 \pm 0.21$ & $0.73 \pm 0.16$ & $0.83 \pm 0.20$ & $0.76 \pm 0.12$ & $0.7 \pm 0.1$ \\
\hline
\end{tabular}

HLHS, Hypoplastic left heart syndrome; DORV, double-outlet right ventricle; $P A-I V S$, pulmonary atresia with intact ventricular septum; D-TGA, dextro-transposition of the great arteries; $S D$, standard deviation; $B S A$, body surface area; $I V C$, inferior vena cava; $S V C$, superior vena cava; $R P A$, right pulmonary artery; $L P A$, left pulmonary artery; $A o$, aorta. All values.

were significantly lower than the measured aortic flows. This may be explained in part by coronary blood flow, which is included in aortic velocity maps when measured near the valve. A more likely explanation for this difference is the presence of significant aortopulmonary collaterals, inasmuch as these collaterals are known to be present in Fontan patients, especially after prolonged pleural effusions. ${ }^{14}$ This difference deserves further investigation. The quantification of collateral flow has classically been quite difficult, and these data point to a potential mechanism of quantifying this flow. Recognizing the potential differences in measured aortic and caval flow is important and has not previously been described.

Another potential source of error in the Fontan pathway flow measurements is in the breath-holding technique used during routine phase contrast magnetic resonance velocity mapping acquisitions. It has been demonstrated that Fontan blood flow, especially the IVC, increases during inspiration and decreases during expiration. ${ }^{15}$ Many of the sequences were acquired during expiratory breath-holds and may account for some of the differences between the aortic and Fontan baffle measurements. However, comparisons between the breath-held and free-breathing patients revealed no significant differences. This suggests that the effects of breath-holding on the flow measurements are likely small.

The increase in IVC fraction with age shown in Figure 1 is consistent with previous studies in normal children. ${ }^{16} \mathrm{~A}$ Doppler study by Salim and associates ${ }^{16}$ in 1995 looked at SVC flow compared with total pulmonary blood flow in a group of 145 healthy children. They determined that the IVC flow reached a nadir of $45 \%$ of total caval flow at 2.5 years of age and then increased to $65 \%$ of the total pulmonary blood flow by 6.6 years of age. Although the IVC contributions were slightly lower than those suggested in our study, the overall trend is quite similar. Note that the initial decline in IVC fraction was not captured in our study be- cause most of our patients were older than 2.5 years of age, whereas the Salim study indicates the nadir occurs. This suggests that the presence of a Fontan does not have a significant effect on the relationship between SVC and IVC contributions of caval flow.

\section{Prior Studies}

To date, very few studies have systematically examined the flow rates and distribution in the Fontan baffle. We are not aware of any series of the magnitude currently being presented.

In 1999, Fogel and colleagues ${ }^{17}$ used CMR presaturation pulse sequences to measure the IVC and SVC flow contribution to each pulmonary artery. In this study, 10 patients underwent CMR with presaturation pulses applied individually to the SVC and IVC, with the relative flow contribution to each pulmonary artery measured using the relative signal decrease. It was shown that in their cohort of 2-year-old children, on average $40 \%$ of the total systemic venous return was from the IVC, with relatively more flow from the IVC directed toward the LPA. This is consistent with our study in which approximately $37 \%$ of the caval flow was from the IVC in this age group (see Figure 1). Absolute flows were not measured in their study. ${ }^{17}$

The largest series to date came from Rosenthal and coworkers ${ }^{11}$ in 1995 . This study used respiratory mass spectrometry with acetylene to measure effective pulmonary blood flow during rest and exercise in 43 patients having the Fontan operation. The resting pulmonary blood flow was measured at $2.2 \mathrm{~L} \cdot \mathrm{min}^{-1} \cdot \mathrm{m}^{-2}$ for atriopulmonary Fontans and $2.3 \mathrm{~L} \cdot \min ^{-1} \cdot \mathrm{m}^{-2}$ for total cavopulmonary connection Fontans. ${ }^{11}$ These data agree very well with our measured total pulmonary blood flow.

Shekerdemian and coworkers ${ }^{13}$ in 1997 studied 14 Fontan patients under conditions of positive- and negative-pressure 

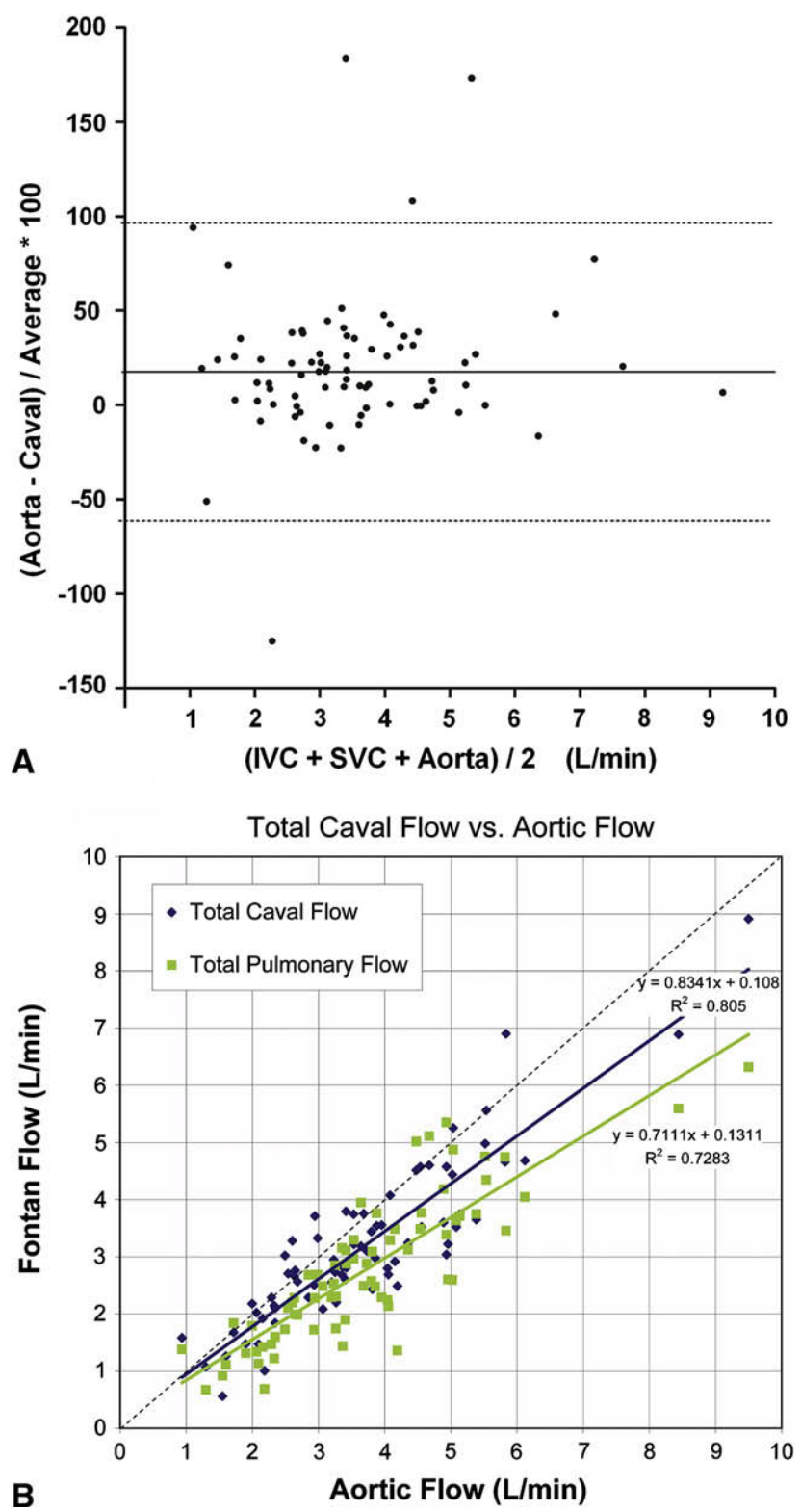

FIGURE 2. A, Bland-Altman of percent difference between measured aortic and caval flow. Note good agreement with the exception of 4 outliers, but with a bias of the aorta being $21 \%$ greater. The difference is not a function of cardiac output. B, Total caval flow and pulmonary flow versus aortic flow with outliers not included. Caval flow shows strong correlation with aortic flow data, $\mathrm{y}=0.83 \mathrm{x}+0.11, r=0.90$. Similarly, pulmonary flow shows strong correlation with aortic flow $(r=0.85) . I V C$, Inferior vena cava; $S V C$, superior vena cava.

ventilation either immediately postoperatively or during elective cardiac catheterization after the Fontan procedure. They measured pulmonary blood flow by direct Fick measurement. The pulmonary blood flow under positive-pressure ventilation was $2.4 \pm 1.1 \mathrm{~L} \cdot \mathrm{min}^{-1} \cdot \mathrm{m}^{-2}$ and under negative-pressure ventilation was $3.5 \pm 1.5 \mathrm{~L} \cdot \min ^{-1} \cdot \mathrm{m}^{-2} \cdot{ }^{13}$

Hjortdal, ${ }^{15}$ Pedersen, ${ }^{18}$ and their associates measured caval and pulmonary blood flow in 11 Fontan patients during rest and exercise. They measured the average total indexed caval blood flow at $2.5 \mathrm{~L} \cdot \mathrm{min}^{-1} \cdot \mathrm{m}^{-2}$ at rest, with $56 \%$ of the flow from the IVC at rest. The indexed pulmonary blood flow was $2.3 \mathrm{~L} \cdot \mathrm{min}^{-1} \cdot \mathrm{m}^{-2}$, which was not significantly different from the caval flows measured in this study.

\section{Limitations}

CMR obtains flow data over multiple heartbeats, and the data therefore represent an average flow over the course of image acquisition (between 15 and 25 seconds). Although correlation with echocardiographic data is possible, it is difficult to draw a one-to-one comparison inasmuch as echocardiography measures instantaneous flows.

The age range of our patient population was 2 to 24 years, and therefore large numbers in individuals in each age bracket are not present. In addition, this was a cross-sectional and not a cohort study, so how flows change in an individual patient over the course of time cannot be gleaned from this data.

This study did not concentrate on outcome based on the measured flows and is a starting point for future investigations regarding the impact of these data. Further follow-up studies in these patients are currently underway.

\section{CONCLUSIONS}

This study demonstrates that in patients having the Fontan procedure, IVC fractional blood flow is a function of age and BSA, similar to normal children. Although there is a wide range, RPA fractional flow is on average $55 \%$ and is not a function of age or BSA. In patients with bilateral SVCs, there is no significant dominance of the right SVC overall and no significant difference in blood flow to each lung. There was no significant effect of SVC anastomosis type on pulmonary blood flow in this study. Although cardiac output measured by aorta or total caval flow was not statistically different between Fontan types, measured pulmonary blood flow was significantly less in intracardiac compared with extracardiac Fontans. There were no significant differences in flows between patients with dominant morphologically left or right ventricles.

The current data demonstrate excellent correlation among all three methods of measuring cardiac output with relatively small errors between them. However, it is important to note that measuring aortic flow may actually significantly overestimate Fontan blood flow in a majority of patients with or without a fenestration. Although a likely reason for this difference is aortopulmonary collaterals, this cannot be proven in the current study. This is an important finding, inasmuch as measuring aortic flow may not adequately characterize the effective systemic output. This is likely better characterized by measuring caval flows, which exclude the relatively ineffective aortopulmonary collateral flow. The difference between aortic and caval flow may provide a way to quantify collateral flow in these patients, which may be an important problem contributing to hemodynamic compromise in a subset of Fontan patients. Further studies are required to 
determine whether this is a reliable method of quantifying aortopulmonary collateral flow.

\section{References}

1. Fontan F, Baudet E. Surgical repair of tricuspid atresia. Thorax. 1971;26:240-8

2. Kreutzer G, Galindez E, Bono H, de Palma C, Laura JP. An operation for the correction of tricuspid atresia. J Thorac Cardiovasc Surg. 1973;66:613-21.

3. Bridges ND, Lock JE, Castaneda AR. Baffle fenestration with subsequent transcatheter closure. Modification of the Fontan operation for patients at increased risk. Circulation. 1990;82:1681-9.

4. de Leval MR, Kilner P, Gewillig M, Bull C. Total cavopulmonary connection: a logical alternative to atriopulmonary connection for complex Fontan operations-experimental studies and early clinical experience. J Thorac Cardiovasc Surg. 1988;96:682-95.

5. di Carlo D, Williams WG, Freedom RM, Trusler GA, Rowe RD. The role of cavapulmonary (Glenn) anastomosis in the palliative treatment of congenital heart disease. J Thorac Cardiovasc Surg. 1982;83:437-42.

6. Kawashima Y, Kitamura S, Matsuda H, Shimazaki Y, Nakano S, Hirose H. Total cavopulmonary shunt operation in complex cardiac anomalies: a new operation. J Thorac Cardiovasc Surg. 1984;87:74-81.

7. Norwood WI, Lang P, Casteneda AR, Campbell DN. Experience with operations for hypoplastic left heart syndrome. J Thorac Cardiovasc Surg. 1981;82:511-9.

8. Beerbaum P, Korperich H, Barth P, Esdorn H, Gieseke J, Meyer H. Noninvasive quantification of left-to-right shunt in pediatric patients: phase-contrast cine magnetic resonance imaging compared with invasive oximetry. Circulation. 2001; 103:2476-82.

9. Beerbaum P, Korperich H, Gieseke J, Barth P, Peuster M, Meyer H. Rapid leftto-right shunt quantification in children by phase-contrast magnetic resonance imaging combined with sensitivity encoding (SENSE). Circulation. 2003;108: 1355-61.

10. Kozerke S, Botnar R, Oyre S, Scheidegger MB, Pedersen EM, Boesiger P. Automatic vessel segmentation using active contours in cine phase contrast flow measurements. J Magn Reson Imaging. 1999;10:41-51.

11. Rosenthal M, Bush A, Deanfield J, Redington A. Comparison of cardiopulmonary adaptation during exercise in children after the atriopulmonary and total cavopulmonary connection Fontan procedures. Circulation. 1995;91:372-8.

12. Shachar GB, Fuhrman BP, Wang Y, Lucas RV Jr, Lock JE. Rest and exercise hemodynamics after the Fontan procedure. Circulation. 1982;65:1043-8.

13. Shekerdemian LS, Bush A, Shore DF, Lincoln C, Redington AN. Cardiopulmonary interactions after Fontan operations: augmentation of cardiac output using negative pressure ventilation. Circulation. 1997;96:3934-42.

14. Triedman JK, Bridges ND, Mayer JE Jr, Lock JE. Prevalence and risk factors for aortopulmonary collateral vessels after Fontan and bidirectional Glenn procedures. J Am Coll Cardiol. 1993;22:207-15.

15. Hjortdal VE, Emmertsen K, Stenbog E, Frund T, Schmidt MR, Kromann O, et al. Effects of exercise and respiration on blood flow in total cavopulmonary connection: a real-time magnetic resonance flow study. Circulation. 2003;108:1227-31.

16. Salim MA, DiSessa TG, Arheart KL, Alpert BS. Contribution of superior vena caval flow to total cardiac output in children: a Doppler echocardiographic study. Circulation. 1995;92:1860-5.

17. Fogel MA, Weinberg PM, Rychik J, Hubbard A, Jacobs M, Spray TL, et al. Caval contribution to flow in the branch pulmonary arteries of Fontan patients with a novel application of magnetic resonance presaturation pulse. Circulation. 1999;99:1215-21.

18. Pedersen EM, Stenbog EV, Frund T, Houlind K, Kromann O, Sorensen KE, et al. Flow during exercise in the total cavopulmonary connection measured by magnetic resonance velocity mapping. Heart. 2002;87:554-8. 